\title{
The Challenge of Language Assessment for African American English-Speaking Children: A Historical Perspective
}

\author{
Harry N. Seymour, Ph.D. ${ }^{1}$
}

\section{ABSTRACT}

The diagnostic problem of how validly to assess the language of children who speak dialects different from Mainstream American English (MAE) has challenged the field of communication disorders for several decades. The key to its solution is to recognize differences due to dialect or development and remove them from the initial diagnosis of a disorder. A new approach to the puzzle, implemented jointly by University of Massachusetts scholars and the Psychological Corporation (TPC), takes two directions: (1) it provides new normative data on African American English (AAE) development, and (2) it proposes a level of analysis deeper than dialect for the discovery of alternate markers of a disorder. We present three objectives for a language assessment instrument designed to solve this longstanding problem: (1) to answer the problem/no problem question for a given child; (2) to provide explanatory data about the nature of the problem; and (3) to achieve objectives 1 and 2 in a way that is culturally and linguistically fair to both speakers of MAE and speakers of other dialects of English such as AAE.

KEYWORDS: Sources of language variation, Mainstream American English (MAE), African American English (AAE), cultural and linguistic bias, contrastive and noncontrastive language features, ASHA's position paper on social dialects

Learning Outcomes: As a result of this activity, the participant will be able to describe (1) the three aspects of language that must be addressed when attempting to validly assess the language of a child who is speaking African American English (AAE), and (2) the clinical problems presented when attempting to validly assess the language of a child who is speaking AAE.

Evaluating Language Variation: Distinguishing Dialect and Development from Disorder; Editors in Chief, Nancy HelmEstabrooks, Sc.D., and Nan Bernstein Ratner, Ed.D.; Guest Editors, Harry N. Seymour, Ph.D., and Barbara Zurer Pearson, Ph.D. Seminars in Speech and Language, volume 25, number 1, 2004. Address for correspondence and reprint requests: Harry N. Seymour, Ph.D., Department of Communication Disorders, University of Massachusetts Amherst, Amherst, MA 01003. E-mail: hseymour@comdis.umass.edu. ${ }^{1}$ Professor Emeritus, Department of Communication Disorders, University of Massachusetts Amherst, Amherst, Massachusetts. Copyright (C) 2004 by Thieme Medical Publishers, Inc., 333 Seventh Avenue, New York, NY 10001, USA. Tel: +1(212) 584-4662. 0734-0478,p;2004,25,01,003,012,ftx,en;ss100178x. 


\section{DEVELOPMENT, DIALECT, OR DISORDER?}

Story A: The big brother has the train. And he beld it up high so be couldn't get it and then he bide... put it under the bed. And then bis little brother, he looked under the bed when his brother was eating his sandwich. And then he put it in his toy box. Then the big brother was thinking about the train, and he looked under the bed, but it wasn't there. (Ages 6;1)

Story B: He's not giving the train back to him. He put it under his bed. He eats a sandwich. He gets his train under his bed. He comes in there. He puts it in his toy box. Then he comes lookin' for it. Then he looks under the bed. (Ages 4;8)

Story C: Once upon a time a little boy wanted to play with the train. And he tryna get the train, but bis mean brother holdin' it up bigh. So the big boy put it under his bed. When the big brother in the

kitchen eatin' his sandwich, the little boy take he train and he put it in his toy box. Then the big boy came back and he thinkin' of the train. And he look under the bed but he don't find nothin'.

(Ages 6;3)

Story D: The big guy... the wittle brother wants to play with the choo-choo train. The big guy hiding it under his bed. The wittle guy... the wittle brother gotten it and the wittle brother putting it in bis toy box. Then the brother came in the door. Then he came look for the toy. Then look under his bed. (Ages 6;7)

The narratives presented above show four very different children. Three of them differ in expected ways. One differs in ways characteristic of a child with a language disorder.

To identify which narrator shows evidence of a language disorder, three aspects of child language variation must be addressed. The evaluation of a disorder must first take into account the child's dialect status and developmental status. In determining which of these narrators has a disorder and is in need of language services, the speech-language pathologist (SLP) must distinguish which elements derive from the child's stage of development, which elements reveal the child's dialect, and which elements indicate disorder.
Making the distinctions among development, dialect, and disorder for the above narratives can represent a difficult diagnostic puzzle. This puzzle is relatively simple when only mainstream American English (MAE) is involved. There is an extensive literature describing the milestones of development and how children learn to use language in appropriately formed narratives as they grow and mature, so the developmental distinction between Story A and Story B is clear. Story A is produced by a 6year-old child and Story B by a 4-year-old child. If a 6-year-old child produced the story in $\mathrm{B}$, it might be cause for concern, but $\mathrm{B}$ is perfectly normal for a 4-year-old child.

On the other hand, Story D is produced by an MAE-speaking 6-year-old child. The syntactic forms are inconsistent and unpredictable; the narrative focuses only on the actions in the pictures and lacks the cohesive devices expected of a child of that age. Again, the diagnostic puzzle is not too difficult to resolve for an MAE-speaking child with a language disorder given the indicators of delay in Story D.

However, in the case of Story C the situation becomes more complicated in that the narrator is not a speaker of MAE and uses stigmatized language forms, which may distract the listener from recognizing the basic quality of the story; and because of various omissions of morphological inflections, this child could be confused with a child who has a language disorder. In fact, Story $\mathrm{C}$ is told by an African American English (AAE) speaker who, like the speaker in Story A, exhibits above average use of narrative markers, such as time clauses (e.g., "when") and sophisticated knowledge of the language of thought (e.g., "he think about. .."). To diagnose the speaker of Story $\mathrm{C}$ as having a disorder would be a serious but not an uncommon mistake if $\mathrm{AAE}$ status were not factored into the diagnosis.

\section{THE DIAGNOSTIC CHALLENGE}

The diagnostic problem associated with the above narratives captures the essence of a clinical conundrum that has challenged communication disorders for several decades. This challenge is how validly to assess children who speak dialects so different from MAE that it is 
difficult to separate them from children with a language disorder. In this issue, solutions to this clinical problem are presented so that the AAE status of Case $\mathrm{C}$ is recognized for what it is, a dialectal variation, and not confused for the disordered status of Case D.

Making this distinction, that is, distinguishing the difference between typically developing MAE- and AAE-speaking children from their language-impaired peers, is the objective of this issue. The objective is achieved through an in-depth discussion of the development, design, and research findings of a project to develop an innovative assessment test for a non-MAE population. This research and the resulting test construction were focused on how best to isolate dialect factors and remove them from the initial diagnosis of risk. The proposed battery exemplifies the separation of two functions: dialect identification and diagnosis of a disorder. These tests and the process they derive from are used here to demonstrate how children, including AAE speakers, can be evaluated fairly and without linguistic or cultural bias.

The dialect-neutral language test described in this issue was developed by Harry Seymour, Tom Roeper, and Jill and Peter de Villiers at the University of Massachusetts Amherst in conjunction with The Psychological Corporation. The extensive research foundation of the test was sponsored by a grant and then a contract from the National Institutes of Health-National Institute on Deafness and Other Communication Disorders to develop a language assessment instrument that would be appropriate and unbiased for African American children who speak AAE. It has taken more than 10 years and the work is not yet finished. Preliminary versions of a screener and a comprehensive language test were published in 2003. A norm-referenced version with a significant sampling of African American children is being developed now for publication in 2005.

\section{Clinical Implications of Dialect Differences}

In general, SLPs rely heavily on a single dialect standard (i.e., MAE) as the referent of acceptability when assessing the language of children. Although MAE is an abstract notion and is not a specific language entity, it is nevertheless perceived to be the variety of English most used in the conduct of commerce and is fostered in the schools as most acceptable. Moreover, the notion of a single MAE is a misnomer in that MAE can vary from one region of the country to another. For example, the MAE spoken in Boston sounds different from the MAE in Georgia.

Indeed, President John F. Kennedy, who dropped his /r/, as in "pak the ka", sounded very different from President Jimmy Carter, whose accent was distinctly southern. Of course these differences are superficial variations of English, and are considered to be MAE even though they represent two very distant communities, a northern city and the rural south. Despite such variations in English speech patterns across the country, there exists a common core of language features that defines who is and is not a speaker of MAE. Hence, differences among MAE speakers are relatively minor and a standard archetype is generally applied by SLPs despite regional variations.

Most variations among dialects of English are relatively superficial, representing simple contrasts from the archetype standard, and thus, present little difficulty to SLPs in accommodating those variations in the assessment process. However, there are a few dialects such as AAE in which there are more profound contrasts from MAE and the assessment process becomes more complicated.

AAE has been described by sociolinguists over the last several decades as a dialect primarily spoken by African Americans. It is variously referred to as Black English, Ebonics, African American English Vernacular, among other names. (The preferred term in this article is AAE, which is commonly used in academic circles.) AAE, like MAE, is but one of many varieties of English. However, unlike MAE, which cuts across geographic, racial, and ethnic boundaries, AAE is characterized by a commonality of speech spoken primarily by African Americans, but not by all of them. AAE is less geographically defined than other dialects of English, though there are some differences by geographic region; rather it has emerged as a commonality of speech and grammar of a culturally defined group. In addition, children or adults of other races who have strong cultural 
identification or primary social interaction with African Americans may speak AAE too. Thus, AAE may be defined in terms of the features that distinguish a pattern of grammar (morphology, semantics, syntax, pragmatics, and phonology) in the speech used by culturally identified African Americans.

\section{The Challenge of AAE Diagnosis}

The clinical problems presented by AAE are 2fold: (1) AAE features appear similar to patterns of language disorders, and (2) there is a paucity of developmental research on AAE. With respect to the first issue, AAE is heavily characterized by optional use of certain linguistic structures, particularly morphological inflections. The term "optional” refers to a speaker's use of a particular linguistic structure at some times and not others. For example, AAE speakers may or may not produce a present tense sentence without a copula verb (i.e., "a zerocopula," He is tall $\rightarrow$ He tall), zero third-person present tense agreement (He walks $\rightarrow$ He walk), and zero past $-e d$ (He played yesterday $\rightarrow$ He play yesterday). Because, it is not uncommon for a language-disordered child to delete copula "is," third person $/-s /$, and past $/-e d /$, it may be difficult, in a diagnostic context, to differentiate such disordered patterns from the typical patterns spoken in AAE.

This differentiation problem is further exacerbated by issue two, the limited information about the course of development of such patterns as copula, third-person $/-s /$, and past -ed. As AAE children's language matures during the acquisition stage, it remains unclear when these and other AAE patterns are mastered and the forms they take. In MAE, there are specific normative milestones that indicate when children of various ages acquire mastery of morphological inflections. These milestones constitute acquisitional benchmarks for SLPs to follow in identifying children who fail to achieve them. A similar set of benchmarks is lacking for AAE-speaking children.

Despite the absence of a comparable dataset for AAE acquisition, undoubtedly there are strong similarities between the two dialects, given that both $\mathrm{MAE}$ and $\mathrm{AAE}$ are spoken by speakers of English. The important question about AAE acquisition is when particular AAE features are mastered. During the acquisitional stage, an informed position is that both AAE and MAE produce very common developmental patterns such as deletions of morphological inflections. ${ }^{1-3}$ As both dialects mature in the process of acquisition, they diverge such that each adopts the adult patterns of its respective system. This means that many of the developmental patterns shared between the dialects become extinct in MAE, but appear to be retained in AAE. For example, at age 3 years, both dialects may produce an absent thirdperson / $/ s /$ agreement marker; at age 5 years this feature no longer exists for the MAE speaking child, but remains in the AAE-learning child's speech at 5 years and older. Because of the optionality of features such as the thirdperson $/-s /$ agreement marker, the point at which a child's production shifts from immature status to adult status has not been determined. ${ }^{4,5}$ At the same time, uniquely AAE elements, such as the use of an invariant form of "to be" to indicate habitual actions, are emerging in the AAE-learning child. Additional complexities such as these intersect with the third-person /-s/ agreement system in ways that have not been investigated. Thus, this acquisition puzzle remains a source of difficulty when assessing child AAE speakers.

\section{HISTORICAL PERSPECTIVE IN ADDRESSING THE CLINICAL PROBLEM}

A debate between John Michels and Orlando Taylor ${ }^{6,7}$ during the 1968 American SpeechLanguage-Hearing Association (ASHA) annual convention brought forward these controversial issues about linguistic and cultural bias in the assessment and treatment of African American children. As a result of this debate and the issues it raised, a small group of African American scholars formed the ASHA Black Caucus. Through the efforts of this Caucus, ASHA was motivated to revise its curriculum requirements for clinical certification by broadening the recommended coursework to include the study of sociolinguistics and the topic of AAE. 
Throughout the 1970s, the Black Caucus continued to push for fair and equitable testing practices and a multicultural perspective in ASHA. By 1978, the Caucus had evolved into the National Black Association for SpeechLanguage and Hearing, an organization that has been very effective in nurturing and disseminating scholarship among African American students, SLPs, and university faculty regarding the communicative styles of African Americans. In addition, the organization has played an important role in the adoption of ASHA's position paper on social dialects, which states “... no dialectal variety of English is a disorder or a pathological form of speech or language." 8,9

ASHA's position paper on social dialects established that SLPs should not view AAE as a deficit. This position was helpful in providing a challenge to the deficit position, which argued that AAE was cognitively corrupt and deficient. ASHA's position paper contradicted this argument and gave support for an opposing position, that AAE was simply different and was a rule-governed dialect of English. Although a significant step forward in acknowledging the legitimacy of AAE, the position paper fell short of telling SLPs what to do about AAE in terms of assessment and treatment of communication disorders among AAE speakers.

The testing practices in communication disorders during the last several decades are such that reliance on standardized tests of language almost ensures that children who speak AAE are likely to be penalized for doing so. One form this penalty takes is a disproportionate representation of African American children in language services and special education programs throughout the country. This was so in 1970 and it prevails to this day.

Consider that across the United States, African American children are three times more likely to be diagnosed as mentally retarded than their white peers. ${ }^{10}$ This disproportionality is also reflected in special education classifications. ${ }^{11}$ African American children comprise $\sim 15 \%$ of the school-age population, yet their numbers in special education for disabilities associated with language functioning constitute an over-representation in every category. All of these educational designations rely at least in part on testing done in the medium of MAE (Fig. 1).

One can reasonably argue that where there is over-representation, there are undoubtedly children who are in fact language disordered and who go undiagnosed. This would be underrepresentation, which, along with over-representation, reflects misdiagnosis and can be attributed in part to an assessment process that is biased against African American and other minority children. This bias can take several forms. ${ }^{12}$ According to $\mathrm{Wyatt}^{13}$ there can be situational bias, format bias, value bias,

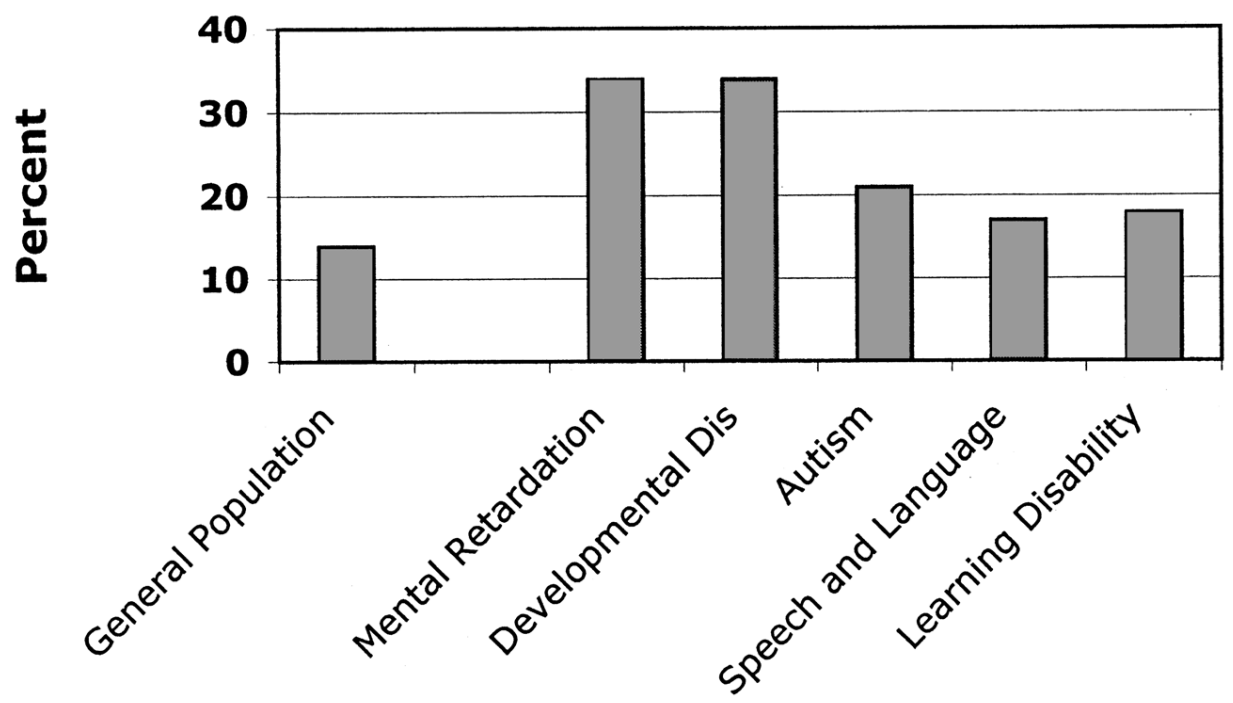

Figure 1 Percent of African American children in special education classifications (Dis, disorder). 
and linguistic bias, all of which create a disconnect between the client and the testing context.

Of these various kinds of bias, perhaps the most difficult to address in the clinical setting is the linguistic and cultural bias. This difficulty stems from the importance and reliance on standardized testing. Because standardized tests typically are normed on racial and ethnic groups in accordance to a demographic distribution that matches the U.S. general population, there is a linguistic and cultural skewing toward the majority group; that is, middle-class white Americans. As a consequence, linguistic and cultural differences associated with dialects such as $\mathrm{AAE}$ are not adequately reflected in the normative distribution of the tests. Thus, AAE speaking children can be and are penalized for their dialect.

\section{MULTICULTURAL MODELS}

Language is clearly a major factor in the kinds of special education disabilities for which African American children are over-represented. This language factor is directly related to the mismatch between the target MAE standard on assessment tests and the AAE status of so many African American children. In recent years and due largely to a society now characterized by diverse ethnic, racial, and language communities, many if not most SLPs recognize that they can no longer apply a single linguistic and cultural model in assessing and treating language disorders in children. Serious consideration must be given to the language background from which children come in determining the kinds of assessment strategies and materials that are most appropriate.

With respect to $\mathrm{AAE}$, these assessment strategies and materials must draw upon existing knowledge about AAE. Much of this knowledge derives from linguistic descriptions about AAE from the early work of sociolinguists during the 1960s and early 1970s. ${ }^{14-21}$ This seminal work became foundational for later descriptive research and for those focusing on the clinical issues concerned with distinguishing language deficits from language differences characterized by AAE. 4,12,22-27

Research on AAE has led to the proposal of several models for assessing AAE-speaking children. Some have suggested abandoning standardized tests for African American children altogether in favor of "nonstandardized" assessment methods. ${ }^{23,28,29}$ Among these methods are language sampling analysis and criterion-referenced language probes. As useful approaches in general, both language sampling and language probes can be recommended specifically for AAE children because their naturalistic and dynamic process can be free of bias compared with the relatively restrictive and artificial testing contexts of standardized tests. However, such approaches carry the disadvantages of being time intensive, possibly less reliable, and having inadequate normative data on AAE.

Because of the limited normative data on $\mathrm{AAE}$ and remaining questions about the system of AAE, some scholars have directed their attention at those linguistic structures that are common to both AAE and MAE. This emphasis avoids AAE features and also avoids the clinical problem regarding the status of optional AAE structures. One such approach is the Minimal Competency Core (MCC) proposed by Stockman. ${ }^{28}$ The MCC identifies a scale of obligatory language patterns expected of all typically developing children regardless of their dialect status. This scale constitutes a criterionreferenced measure representing the lowest end of a competency scale against which acceptable language performance can be measured. In addition, Craig and Washington ${ }^{30}$ focus on complex sentence constructions common to both AAE and MAE. This approach avoids zero morphosyntax patterns so typical of AAE. There is also support for avoiding AAE features in the diagnostic process in the work of Seymour, Bland-Stewart, and Green, ${ }^{31}$ who showed that AAE features that contrast with MAE were less effective in identifying language disorders among African American children than features that were noncontrastive between AAE and MAE

This contrastive/noncontrastive analysis, first proposed by Seymour and Seymour in $1977,{ }^{4}$ introduced a diagnostic procedure that focuses entirely on those language structures that $\mathrm{AAE}$ and MAE have in common; that is, those that are noncontrastive. The underlying assumptions for this approach are (1) AAE and 
MAE are more similar than they are different; (2) specific AAE features should be avoided because they represent patterns that appear similar to disordered features, and thus would be ambiguous in the diagnostic process; and (3) an impaired language system also will reflect itself in the similarities between AAE and MAE. The intention was that this noncontrastive emphasis would answer the problem/ no problem question in diagnosis; that is, is there a problem or not? It was fully recognized that to determine the nature of the language problem, a complete diagnosis should then involve the child's full array of language strengths and weaknesses, which would, by necessity, involve both contrastive and noncontrastive language structures. The problem in implementing such a scheme and in the absence of standardized tests was that a clinician would have to employ time-consuming and technically challenging linguistic analysis associated with language sampling and language probes. As a consequence, too often the clinician has to rely on existing standardized tests as a default procedure to both answer the problem/no problem question and to determine the nature of the problem. The consequence is a perpetuation of inappropriate and biased practices for AAE-speaking children.

\section{THE PROPOSED SOLUTION}

At the heart of the clinical problem associated with dialects such as AAE is the issue of variation. SLPs must examine and interpret at least three important sources of variation when diagnosing language disorders in children. These are variation due to speech and language development, variation due to speech and language dialects, and variation due to speech and language disorder. These sources of variation account for how children's language may differ from the adult model, and adequate assessment must first deal with the evaluation of that language variation.

A test designed to determine sources of linguistic variation must fulfill three objectives: (1) to answer the problem/no problem question; (2) to provide explanatory and evidentiary data about the nature of the problem; and (3) to achieve objectives 1 and 2 in a way that is culturally and linguistically fair to both speakers of MAE and speakers of other dialects of English such as AAE. Our proposed battery (see Acknowledgments) meets these objectives by splitting the process in two: Step 1 starts with dialect identification, elicited with contrastive structures; Step 2 follows with dialectneutral diagnosis of disorder. Once dialect identification has been accomplished in the first step of the process, the second part of the screening can concentrate on the diagnostic function. For this, diagnostic test items avoid superficial contrasts between dialects of English by focusing on structures that are noncontrastive and by drawing upon deep principles of language considered universal across dialects and even languages. Such items will be among the most difficult and challenging for children-although they are also among the most effective as language assessment tools.

Most tests of language address the problem/no problem question only and offer little to no explanation about the nature of the child's problem. ${ }^{32}$ The reason for this limited focus is the fragmented and atheoretical properties of the items composing the tests. Typically, language test items are selected for their capacity to measure a discrete aspect of language and provide a developmental differentiation across ages. Consequently, the outcome measures are gross indices of a child's knowledge. Our proposed assessment, on the other hand, will be a process-driven comprehensive test of language composed of test items that are theoretically coherent within language domains. Hence, the outcome measures for children will yield rich information about the child's understanding of processes as opposed to discrete and unrelated bits of language.

If the proposed battery is an effective assessment regardless of the child's dialect and thus could be given to any child, one might question why it is necessary to evaluate Language Variation Status. However, in the case of AAE-speaking children, there are still compelling reasons to determine a child's variation status. First, it helps document which individuals within the African American community are mainstream speakers. Race alone is not 
a sufficient indication. Among the African American subjects in our field-testing research, for example, $15 \%$ percent were identified as MAE speakers by the screener (and fewer than $20 \%$ of those children were recognized as MAE speakers by their teachers). A teacher's knowledge that a child speaks MAE or not can be useful in general educational programming, such as in planning reading instruction. Furthermore, the greatest value of documenting a child's dialect is to the nonimpaired AAE speakers. They cannot be considered impaired solely on the basis of the finding that they do not speak MAE. If their risk status is high, then those children need further evaluation to make a diagnosis of impairment, and that evaluation should not be made with a test normed on MAE speakers.

\section{CONCLUSION}

In brief, the authors represented in this issue have designed an assessment process that consists of three tests appropriate for both MAE and non-MAE speakers between the ages 4 and 9 years. This issue is designed to share our developmental process with researchers and clinicians, and to further the development of additional dialect-sensitive measures. The first measure is a short screener with two parts: one part is designed to identify Language Variation Status in terms of whether a child is an MAE speaker or not, and the second part is designed to identify children who may be at risk for a disorder (Diagnostic Risk Status). The follow-up test is longer and provides criterionreferenced cut-off scores for a comprehensive assessment of syntax, semantics, pragmatics, and phonology. (See Figure 1 in Seymour and Pearson, this issue.) A norm-referenced version, essentially identical in composition to the criterion-referenced version, is projected for 2005. The norm-referenced sample for the test will incorporate a comparison to an oversampling of African American children, and thus will be the only test of language with a significant African American representation. How such tests and future assessment measures make possible a valid and unbiased assessment of children's language is fully described in the articles to follow.

\section{Editor's Note}

The material in this issue pertains especially to $\mathrm{AAE}$ and its speakers. Preliminary research indicates that certain other dialects of English, such as Cajun English and Appalachian English, share many features with AAE, and in pilot testing those children performed like AAE speakers on the proposed tests. However, the utility of such tests for speakers of Spanishinfluenced English has not been established. In principle, young Hispanics in the process of learning English are using an "interlanguage," which is only partly English. Therefore, there is no reason to expect that the deep syntactic principles found in the tests described here will be realized in the interlanguage(s) in the same way that they are in varieties of English. On the other hand, if the Hispanic child has mastered MAE sufficiently to score in the MAE range in Language Variation Status, there is no reason she or he cannot be evaluated using the these instruments. However, the wider range of Hispanic-background children will be better served by a test designed for children in their circumstance, like the one currently under development by Iglesias et al. ${ }^{33}$

\section{ACKNOWLEDGMENTS}

This work was funded in part by National Institutes of Health (NIDCD) under Contract \# N01 DC8-2104 and Grant \# R01 DC 0217204 to Harry Seymour, Principal Investigator, at the University of Massachusetts Amherst, with Thomas Roeper and Jill de Villiers at the University of Massachusetts and Smith College, as co-investigators. It was accomplished in conjunction with The Psychological Corporation of Harcourt Assessment, Inc., San Antonio, TX.

The tests that are the products of this research collaboration are the Diagnostic Evaluation of Language Variation (DELV) assessments, the DELV Screening Test, DELV Criterion-Referenced edition, and the DELV Norm-Referenced edition. The phrase "evaluating language variation" refers generally to the assessment processes discussed in this issue. The term $D E L V$ is the name trademarked by The Psychological Corporation of Harcourt Assessment, Inc., and refers to the specific tests 
that are the outcome of the extensive research described in this article. The specific tests are referred to as the $D E L V-S T$, or "screener," or the $D E L V-C R, D E L V-N R$, or the "full diagnostic test," as appropriate. Questions about the principles underlying the tests can be referred to the authors of this issue (Seymour, Roeper, de Villiers, de Villiers, Pearson, and Ciolli). Questions about the tests themselves should be addressed to the Project Leader at The Psychological Corporation of Harcourt Assessment, Inc.; Lois Ciolli, Senior Research Director.

\section{REFERENCES}

1. Cole L. A developmental analysis of social dialect features in the spontaneous language of preschool Black children. Dissertation, Northwestern University. Evanston, IL; 1980

2. Kovac C. Children's acquisition of variable features. Dissertation. Georgetown University, Wash., DC; 1980

3. Blake I. Language development in working-class black children: An examination of form, content, and use [dissertation]. 1984

4. Seymour HN, Seymour CM. A therapeutic model for communicative disorders among Black English speaking children. J Speech Hear Dis 1977;42:247256

5. Seymour HN, Seymour CM. Black English and standard American English contrasts in consonantal development for four and five-yearolds. J Speech Lang Hear Dis 1981;46:274-280

6. Michel J. The role of ASHA in social, political, and moral activities. ASHA 1969;11:219-220

7. Taylor O. Social and political involvement of the American Speech and Hearing Association. ASHA 1969;11:216-218

8. American Speech-Language-Hearing Association Position paper: Social dialects and implications of the position on social dialects. ASHA 1983; 25:23-27

9. American Speech-Language-Hearing Association. Technical Report: American English Dialects. ASHA 2003; (suppl 23): (In press)

10. Parrish T. Racial disparities in the identification, funding, and provision of special education. In: Losen DJ, Orfield G, eds. Racial Inequity in Special Education, The Civil Rights Project at Harvard University. Cambridge: Harvard Education Press; 2002

11. Losen DJ, Orfield G, eds. Racial Inequity in Special Education, The Civil Rights Project at
Harvard University. Cambridge: Harvard Education Press; 2002

12. Taylor O, Payne K. Culturally valid testing: a proactive approach. Topics Lang Disord 1983;3:8-20

13. Wyatt TA. Assessing the communicative abilities of clients from diverse cultural and language backgrounds. In: Battle DE, ed. Communication Disorders in Multicultural Populations, 3rd ed. Boston: Butterworth-Heinemann; 2002:415-459

14. Shuy R, ed. Social dialects and language learning: Proceedings of the Bloomington, Indiana Conference, August 1964. Champaign, IL: National Council of Teachers of English; 1965

15. Stewart W. Urban Negro speech: Sociolinguistic factors affecting English teaching. In: Shuy R, ed. Social Dialects and Language Learning: Proceedings of the Bloomington, Indiana, Conference, 1964. Champaign, IL: National Council of Teachers of English; 1965:10-19

16. Baratz JC. Language and cognitive assessments of Negro children: assumptions and research needs. ASHA 1969;11:87-91

17. Wolfram W. A Sociolinguistic Description of Detroit Negro Speech. Washington DC: Center for Applied Linguistics; 1969

18. Labov W. The logic of non-standard English. In: Williams F, ed. Language \& Poverty. Chicago: Markham; 1970:153-189

19. Dillard JL. Black English: Its History and Usage in the United States. New York: Random House; 1972

20. Kochman T, ed. Rappin and Stylin Out: Communication in Urban Black America. Chicago: University of Illinois Press; 1972

21. Smitherman G. Talkin and Testifyin: The Language of Black America. Boston: HoughtonMifflin; 1977

22. Adler S. Dialectal differences: professional and clinical implications. J Speech Hear Disord 1971;36:90-100

23. Seymour HN, Miller-Jones D. Language and cognitive assessment of Black children. In: Lass $\mathrm{N}$, ed. Speech and Language Advances in Basic Research and Practice. New York: Academic Press; 1981:203-263

24. Terrell S, Terrell F. Distinguishing linguistic difference from disorders. Topics Lang Disord 1983;3:1-7

25. Vaughn-Cooke F. Improving language assessment in minority children. ASHA 1983;25:29-34

26. Stockman IJ, Vaughn-Cooke F. Implications of semantic category research for language assessment of nonstandard speakers. Top Lang Disord 1986; 6:15-25

27. Craig HK, Washington JA. An assessment battery for identifying language impairments in African American children. J Speech Lang Hear Res 2000; 43:366-379 
28. Stockman I. The promise and pitfalls of language sample analysis as an assessment tool for linguistic minority children. Lang Speech Hear Serv Sch 1996;27:355-366

29. Leonard L, Weiss A. Application of nonstandardized assessment procedures to diverse linguistic populations. Top Lang Disord 1983;3:35-45

30. Craig HK, Washington JA. The complex syntax skills of poor, urban, African American preschoolers at school entry. Lang Speech Hear Serv Sch 1994;25:181-190

31. Seymour HN, Bland-Stewart L, Green L. Difference versus deficit in child African American English. Lang Speech Hear Serv Sch 1998;29: 96-108
32. Muma JR. Language Handbook: Concepts, Assessment, Intervention. Englewood Cliffs, NJ: Prentice Hall; 1978

33. Iglesias A, Peña E, Gutierrez-Clellen V, Bedore L, Goldstein B. Development of a language test for bilingual Spanish-English speaking children. (The Bilingual English/Spanish Assessment, BESA). Paper presented at: the American Speech-Language-Hearing Association Convention, San Francisco, CA, Nov. 18-21, 1999

34. The Council for Exceptional Children and the National Alliance of Black School Educators Addressing Over-Representation of African American Students in Special Education. Washington, DC; 2002:6 